Check for updates

New York

Cite this as: BMJ2021;373:n1079 http://dx.doi.org/10.1136/bmj.n1079 Published: 26 April 2021

\section{Covid-19: US authorises Johnson and Johnson vaccine again, ending pause in rollout}

\author{
Janice Hopkins Tanne
}

The US Food and Drug Administration approved the Johnson \& Johnson (J\&J) single dose covid-19 vaccine on 23 April after a cautionary 10 day pause to consider the risk of blood clots.

Administration of the vaccine began immediately but came with a handout warning of the risk of clots in women under $50 .{ }^{1}$ The vaccine is made by J\&J's subsidiary, Janssen.

Janet Woodcock, acting FDA commissioner, said at a press conference, "We have concluded that the known and potential benefit of the ... vaccine outweigh[s] its known and potential risks in individuals 18 years of age and older." Rochelle Walensky, director of the Centers for Disease Control and Prevention (CDC), said that she supported the FDA's decision.

The J\&J vaccine requires only one dose and does not need to be stored in freezers, making it easier to administer widely.

The FDA's Advisory Committee on Immunization Practices voted by 10-4, with one abstention, to allow use of the vaccine in people over 18 . It called for a handout warning of the small risk of blood clots to be given to people who were about to receive the vaccine. It said that women who decided not to take the vaccine should be offered an alternative, the Pfizer-BioNTech or Moderna vaccine, at the same vaccination site. $^{2}$

\section{Symptoms and treatments}

Among the nearly eight million people in the US who have received the J\&J vaccine, 15 unusual blood clots have been reported-all in women. Another was reported in a man during clinical trials. The blood clots in the brain were described as thrombosis with thrombocytopenia syndrome. Heparin, a common treatment for blood clots, was contraindicated in this situation.

The CDC will hold a telephone briefing for doctors this week to describe symptoms and treatments and will also publish information in the Morbidity and Mortality Weekly Report (MMWR). Most patients affected developed a severe headache within a few days to a few weeks after receiving the vaccine. ${ }^{2}$ The Society for Hematology has published information on recognising and treating the problem. ${ }^{3}$

Leana Wen, former health commissioner for Baltimore, wrote in the Washington Post that younger women should be warned against the J\&J vaccine. "There should be an explicit warning against the vaccine's use in women under the age of 50. I'm in this group," she wrote, saying that she had been in the clinical trial but had received a placebo. "If I knew then what I know now, I would have chosen the Pfizer or Modern vaccines instead." Only two women with blood clots had been taking oral contraceptives, a known risk factor for blood clots, she said. ${ }^{4}$

\section{Hesitancy}

Paul Sax, a Harvard infectious disease specialist, commented in NEJM Journal Watch, "These are not your typical blood clots. The cases are very serious . .. They are rare. The risk is higher in younger women. They occurred shortly after the vaccine.

"Similar thrombotic events occurred with the AstraZeneca covid-19 vaccine ... No cases have yet occurred with the mRNA vaccines [the Pfizer-BioNTech and Moderna vaccines]. ${ }^{5}$

As of 25 April about 140 million Americans had received at least one dose of a covid-19 vaccine, including nearly 95 million people who have been fully vaccinated, either with the one dose J\&J vaccine or with the two dose vaccines made by Pfizer-BioNTech and Moderna. The US has a population of about 330 million.

Daily vaccine doses have fallen to about 2.75 million a day, down from a high of nearly 3.4 million two weeks ago. ${ }^{6}$ The problem now is hesitancy to take the vaccine, which is higher in areas that voted for Donald Trump in the presidential election.

US Food and Drug Administration. FDA and CDC lift recommended pause on Johnson \& Johnson (Janssen) covid-19 vaccine use following thorough safety review (news release). 23 Apr 2021. https://www.fda.gov/newsevents/press-announcements/fda-and-cdc-lift-recommended-pause-johnson-johnson-janssen-covid-19-vaccine-use-following-thorough.

2 Fox M. CDC, FDA lift pause on using J\&J's coronavirus vaccine, add safety warning. CNN.com. 23 Apr 2021.

https://www.cnn.com/2021/04/23/health/johnson-vaccine-acip-recommendation/index.html.

3 Society of Hematology. Covid-19 resources. Hematology diagnosis and treatment of thrombosis with thrombocytopenia following the Janssen COVID-19 vaccine. 25 Apr 2021. https://www.hematology.org/covid-19.

4 Wen L. Opinion: It's good to resume the J\&J vaccine. But younger women should be warned against it. Washington Post2021 Apr 24. https://www.washingtonpost.com/opinions/2021/04/24/its-good-resumejj-vaccine-younger-women-should-be-warned-against-it/.

5 Sax P. Physician's First Watch: Paul Sax on J\&J vaccine decision. NEJM Journal Watch 2021 Apr 25. FirstWatch@jwatch.org.

6 See how the vaccine rollout is going in your county and state. New York Times 2021 Apr 25. https://www.nytimes.com/interactive/2020/us/covid19-vaccine-doses.html.

This article is made freely available for use in accordance with BMJ's website terms and conditions for the duration of the covid-19 pandemic or until otherwise determined by BMJ. You may use, download and print the article for any lawful, non-commercial purpose (including text and data mining) provided that all copyright notices and trade marks are retained. 